\title{
Caracterização de fungos isolados da região Amazônica quanto ao potencial para produção das enzimas envolvidas na conversão da biomassa vegetal
}

\author{
Characterization of fungi isolated from the Amazon region for the \\ potential of biomass-degrading enzymes production
}

\author{
Rosangela Donizete Perpetua Buzon Pirota, II Mariana Tonelotto, II

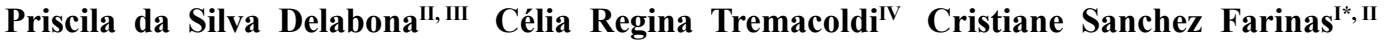

\section{RESUMO}

A conversão da biomassa vegetal proveniente de residuos agroindustriais e florestais em biocombustiveis e bioprodutos, dentro do conceito de biorrefinarias, é de grande interesse, principalmente para o Brasil, onde a agroenergia possui um enorme potencial de desenvolvimento. Entretanto, para garantir a viabilidade do processo de conversão, é fundamental reduzir o custo das enzimas utilizadas na etapa de hidrólise. Para isso, devese dispor da peça chave deste processo, que é o microrganismo. Nesse contexto, o objetivo deste trabalho foi avaliar fungos isolados da região Amazônica em relação ao potencial de produção das enzimas celulases exilanases. De um total de 40 isolados cultivados por fermentação em estado sólido (FES), durante 10 dias, os fungos que se destacaram quanto à produção de endoglucanase (351,79 $\mathrm{Ug}^{-1}$ em 120h) e $\beta$-glicosidase $\left(62,31 \mathrm{Ug}^{-1} \mathrm{em} 72 \mathrm{~h}\right)$ foi o P47C3 (A. niger), e na produção de xilanase $\left(1076,94 \mathrm{Ug}^{-1} \mathrm{em}\right.$ 72h) e FPase $\left(2,46 \mathrm{Ug}^{-1}\right.$ em 120h) foram o P6B2 (A. oryzae) e o $P 40 B 3$, respectivamente. Os resultados obtidos demonstram o enorme potencial de aplicação das enzimas produzidas pelos fungos isolados da Amazônia, contribuindo, assim, para gerar os avanços tecnológicos necessários para o aumento da eficiência do uso da biomassa vegetal como fonte de energia renovável.

Palavras-chave: Amazônia, enzimas, celulases, xilanases, fermentação em estado sólido, agroenergia.

\section{ABSTRACT}

The conversion of biomass from forestry and agroindustrial residues into biofuels and bioproducts, within the biorefinery concept, is of great interest, especially to Brazil, where bioenergy has a huge potential for development. However, to ensure the viability of the conversion process it is essential to reduce the cost of the enzymes used in the hydrolysis step. For this, one must have the key element of this process, which is the microorganism.
In this context, the objective of this study was to evaluate different fungi isolated from the Amazon region for their potential in terms of the production of cellulase and xylanase enzymes. Of a total of 40 strains cultivated under solid state fermentation (SSF) for 10 days, the strain that stood out for the production of endoglucanase (351.79Ug-120h) and $\beta$-glucosidase $\left(62.31 \mathrm{Ug}^{-1}\right.$ at $\left.72 \mathrm{~h}\right)$ was P47C3 (A. niger) whereas for xylanase (1076.94Ug $\mathrm{g}^{-1}$ in 72 hours) and FPase (2.46Ug-1 in 120 hours) were P6B2 (A. oryzae) and $P 40 B 3$, respectively. These results demonstrate the great potential application of the enzymes produced by the Amazon isolated fungi, thus contributing to generate the necessary technological advances in order to increase the efficiency of the use of biomass as a renewable energy source.

Key words: Amazon, enzymes, cellulases, xylanases, solid-state fermentation, bioenergy.

\section{INTRODUÇÃO}

Em um país como o Brasil, onde a agricultura é a principal atividade econômica, os resíduos e subprodutos agrícolas, agroindustriais e florestais são extremamente abundantes. A conversão dessa biomassa vegetal em produtos de valor comercial poderá, além de contribuir para a remoção de poluentes ambientais, trazer grandes dividendos à economia. Dessa forma, uma das possibilidades promissoras de utilização desses materiais lignocelulósicos é a sua conversão em biocombustíveis e outros bioprodutos, dentro do conceito de biorrefinarias (KAMM \& KAMM, 2004).

IEmbrapa Instrumentação, CP 741, 13560-970, São Carlos, SP, Brasil. E-mail: cristiane.farinas@embrapa.br. *Autor para correspondência. IPrograma de Pós-graduação em Biotecnologia (PPG-Biotec), Universidade Federal de São Carlos (UFSCar), São Carlos, SP, Brasil.

IIILaboratório Nacional de Ciência e Tecnologia do Bioetanol (CTBE), Campinas, SP, Brasil.

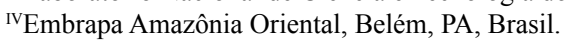


No entanto, para garantir a viabilidade econômica do processo de conversão, é fundamental reduzir o custo das enzimas utilizadas na etapa de hidrólise da biomassa. Para isso, deve-se dispor da peça chave desse processo, que é o microrganismo produtor de enzimas.

A seleção de microrganismos produtores das enzimas envolvidas na degradação da biomassa vegetal, como as celulases e xilanases, é uma das possíveis estratégias para contribuir com a viabilização da produção do etanol celulósico. Nesse sentido, o Brasil se destaca em biodiversidade, tendo um vasto campo a ser explorado na busca de microrganismos que apresentem as características desejadas para tal aplicação. Dentre os diferentes biomas do país, o bioma Amazônico representa uma fonte em potencial de microrganismos, devido às suas condições edafoclimáticas peculiares, que propiciam a constante degradação da biomassa rasteira da floresta. Apesar desse enorme potencial, a literatura relacionada a esse tema ainda é bastante escassa. MEDEIROS et al. (2003) isolaram 10 espécies de fungos da floresta Amazônica e avaliaram sua capacidade de produzir as enzimas xilanases durante o crescimento em meio líquido. SOUZA et al. (2008) estudaram a produção de enzimas por linhagens de Basidiomicetos oriundas de áreas de floresta da Amazônia, sendo possível detectar a produção de celulases e proteases por todos os isolados. Além disso, $40 \%$ das linhagens produziram amilases, $50 \%$ produziram fenoloxidases e $10 \%$ produziram pectinases. DURAN et al. (1995) utilizaram a técnica de triagem em placas para avaliar a atividade de xilanase produzida a partir de 18 espécies de Penicillium e 10 espécies de Aspergillus, isolados da região Amazônica. No entanto, o número de isolados avaliados nesses trabalhos é ainda pequeno, comparado ao potencial que o bioma Amazônico oferece.

As tecnologias existentes para a produção de enzimas por microrganismos utilizam processos fermentativos que podem ser conduzidos tanto no estado líquido, chamados de fermentação submersa (FS), como também no estado sólido, chamados de fermentação em estado sólido (FES). O uso da FES tem se mostrado particularmente vantajoso para o crescimento de fungos filamentosos, uma vez que simula o habitat natural desses microrganismos. Essa vantagem é estendida à produção de enzimas, proporcionando uma maior produtividade, quando comparada à FS (HOLKER et al., 2004). No entanto, não há ainda relatos de estudos que tenham buscado aliar as vantagens dos cultivos em estado sólido para a caracterização abrangente de fungos isolados do bioma Amazônico em relação ao potencial de produção das enzimas envolvidas na degradação da biomassa vegetal. Embora seja muitas vezes considerado que biomassa vegetal possui uma composição uniforme, pode haver uma substancial diversidade na sua composição. Compatível com a diversidade na composição da biomassa vegetal, os microrganismos evoluíram inúmeras estratégias para atacar os componentes da parede celular, apresentando, assim, um arsenal enzimático capaz de realizar a degradação da biomassa vegetal. Esse complexo de enzimas é necessário, devido à elevada recalcitrância dos materiais lignocelulósicos, sendo que esses coquetéis enzimáticos possuem celulases, hemicelulases, pectinases e outras enzimas acessórias atuando de forma sincronizada e sinérgica no processo de degradação (LYND et al., 2002). As celulases formam um complexo de enzimas que atua na conversão do polímero insolúvel de celulose em açúcares fermentescíveis. O mecanismo de hidrólise enzimática da celulose mais aceito descreve a ação sinérgica de pelo menos três classes de enzimas: as endoglucanases, as exoglucanases e as $\beta$-glicosidases ou celobiases (ZHANG \& LYND, 2004). As xilanases (endo1,4 - $\beta$-xilanase) s yo as enzimas responsáveis pela degradação da xilana, que é tipo mais abundante de hemicelulose (DODD \& CANN, 2009). Além disso, as enzimas celulases e xilanases possuem uma ampla variedade de aplicações biotecnológicas nas indústrias de alimentos, ração animal, têxteis, papel e celulose e outros setores (BHAT, 2000).

Nesse contexto, o presente trabalho teve como objetivo caracterizar 40 isolados de fungos da Floresta Amazônica em relação ao potencial de produção das enzimas envolvidas na degradação da biomassa vegetal. Para isso, os 40 isolados foram cultivados em fermentação em estado sólido (FES) durante 10 dias e os extratos enzimáticos produzidos durante esse período foram quantificados em termos das atividades de endoglucanase, $\beta$-glicosidase, FPase e xilanase e comparados em termos dos parâmetros produção e produtividade enzimática.

\section{MATERIAL E MÉTODOS}

Um total de 40 isolados de fungos foi avaliado quanto à produção (U/g de substrato) e produtividade enzimática $\left(\mathrm{Ug}^{-1} \mathrm{~h}\right)$ em FES. Os fungos avaliados foram isolados do solo e de madeira em decomposição da região Amazônica, conforme descrito em (DELABONA et al., 2012). Os isolados são mantidos em placas em meio PDA à temperatura ambiente. 
A FES foi conduzida a $35^{\circ} \mathrm{C}$ por 10 dias em frascos Erlenmeyer de $250 \mathrm{~mL}$, contendo $5 \mathrm{~g}$ de farelo de trigo, sendo que as primeiras amostras foram retiradas em $24 \mathrm{~h}$ e todas as outras a cada 48h. O material foi inoculado com $10^{7}$ esporosg $^{-1}$ de substrato. Após a inoculação dos esporos, foi adicionada aos frascos a solução nutriente modificada de (MANDELS \& STERNBERG, 1976), até a obtenção de uma umidade de $60 \%$ (massa/volume). Após o período correspondente de fermentação de cada amostra, foram adicionados ao material fermentado $50 \mathrm{~mL}$ de tampão citrato de sódio $50 \mathrm{mM}$, $\mathrm{pH} 4,8$, sendo este homogeneizado e posteriormente agitado por 30 minutos a 100rpm. O material foi então filtrado e centrifugado e o sobrenadante foi utilizado como solução enzimática bruta.

Os extratos enzimáticos foram analisados para quantificação das atividades de celulase e xilanase. A atividade de FPase foi analisada segundo GHOSE, 1987. A atividade de endoglucanase foi medida em mistura de reação contendo $0,1 \mathrm{~mL}$ do extrato enzimático bruto e $0,9 \mathrm{~mL}$ de uma solução de $4 \%$ de carboximetilcelulose (CMC, Sigma, EUA) em tampão citrato de sódio $0,05 \mathrm{M}$ e pH 4,8. Essa mistura foi incubada a $50^{\circ} \mathrm{C}$ por 10 minutos. $A$ atividade da xilanase foi determinada de maneira similar à endoglucanase, exceto que $1 \%$ de uma solução de xilana (xilana de faia, Sigma, EUA) foi utilizada como substrato em tampão acetato de sódio $0,1 \mathrm{M}$ e $\mathrm{pH} 5,0$. Os açúcares redutores foram quantificados pelo método DNS (3,5-ácido dinitrosalicílico), segundo MILLER, 1959. A atividade de $\beta$-glicosidase foi realizada usando $0,5 \%$ de solução de celobiose (Sigma) como substrato e os açúcares liberados foram quantificados a partir do Kit de glicose (Laborlab, São Paulo, Brasil).

\section{RESULTADOS E DISCUSSÃO}

Um total de 40 isolados de fungos da região Amazônica foi caracterizado quanto à produção $\left(\mathrm{Ug}^{-1}\right.$ de substrato) e produtividade enzimática $\left(\mathrm{Ug}^{-1} \mathrm{~h}\right)$ em termos das atividades de endoglucanase, $\beta$-glicosidase, FPAse e xilanase, conforme apresentado nas figuras 1, 2, 3 e 4, respectivamente. A seleção dos parâmetros produção e produtividade para a comparação dos resultados se deve ao interesse de aplicação industrial dessas enzimas. Nesse sentido, o parâmetro produtividade se destaca por levar em consideração o tempo de cultivo necessário para a obtenção de determinada atividade enzimática.

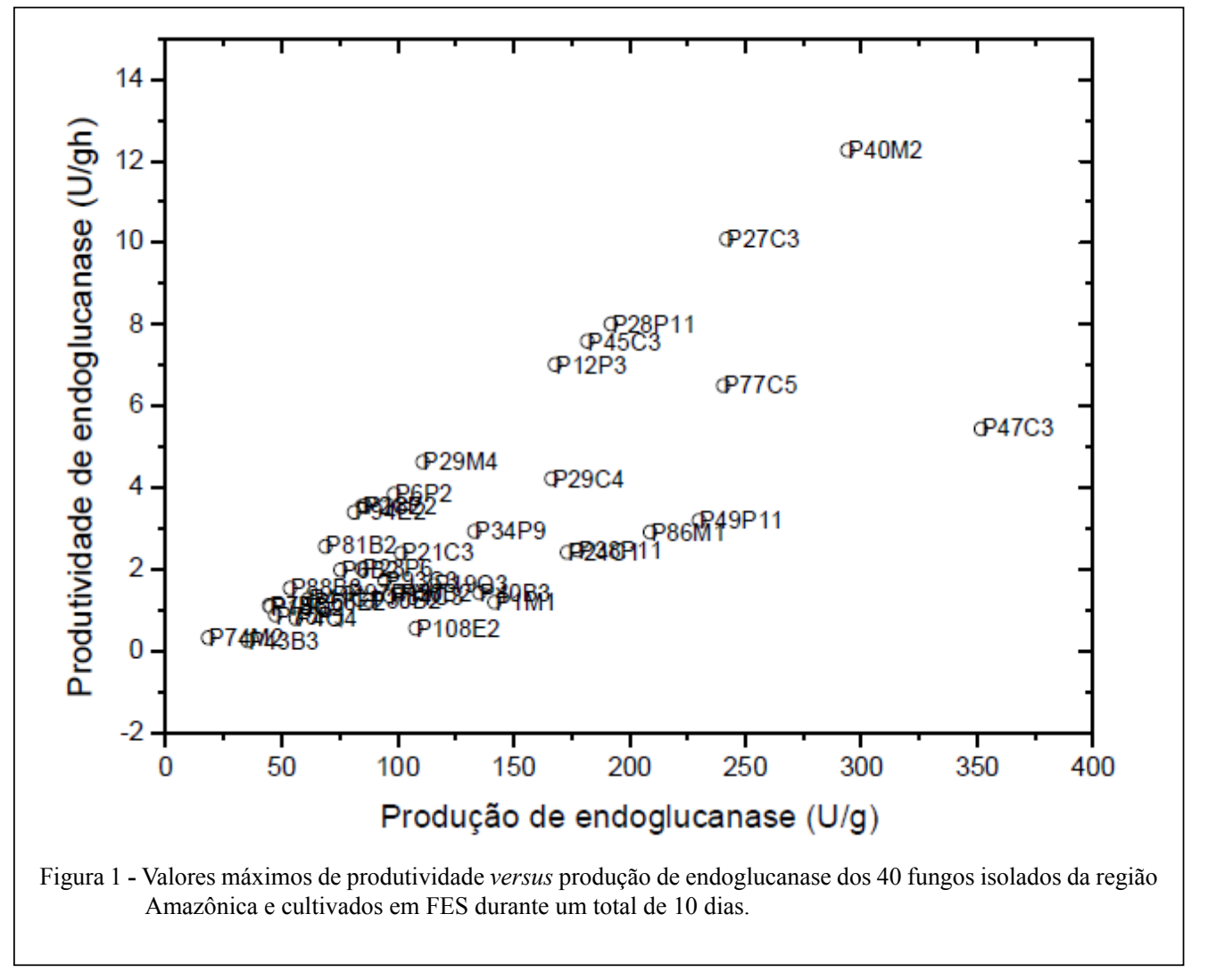

Ciência Rural, v.45, n.9, set, 2015. 


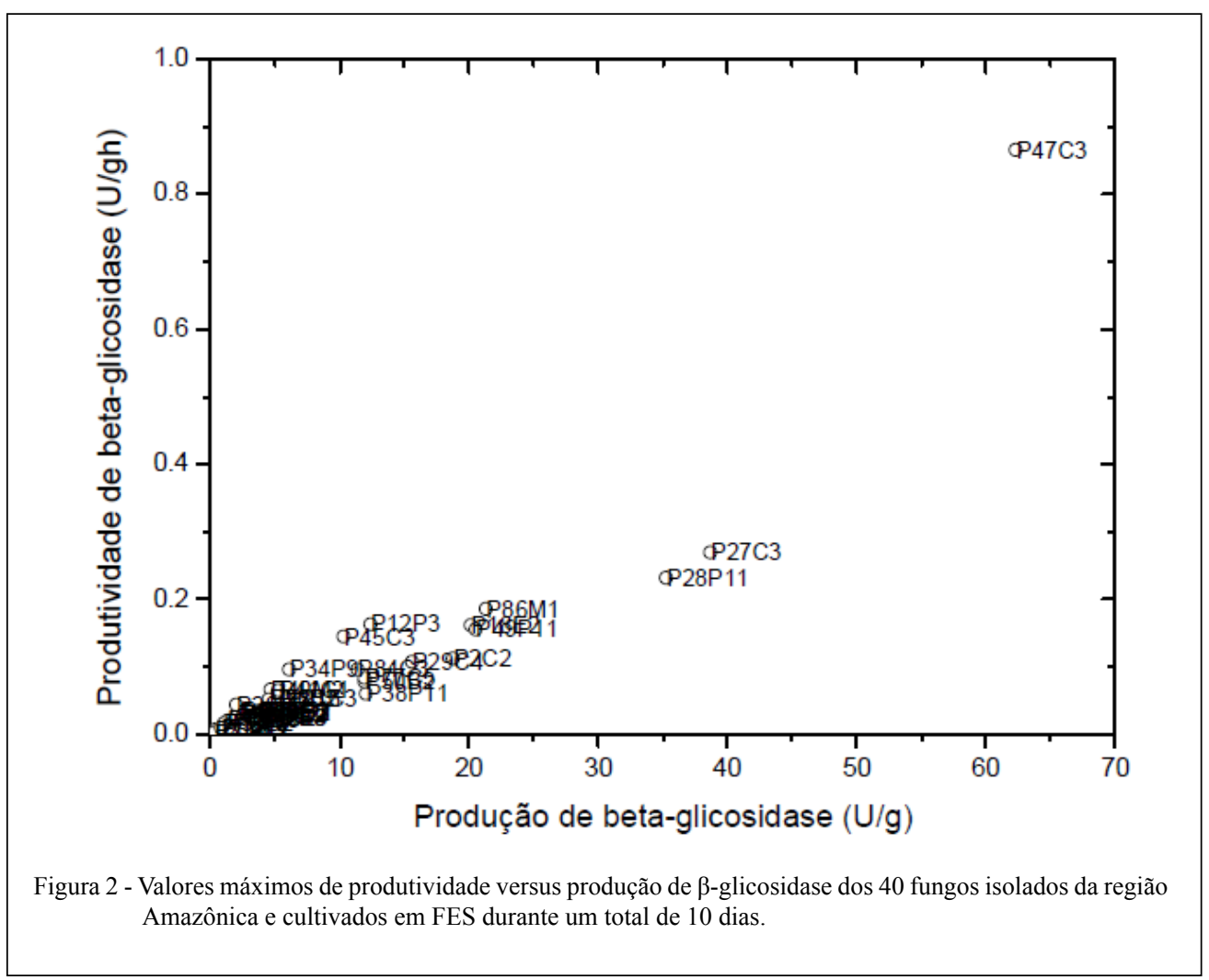

Com relação ao perfil da atividade de endoglucanase (Figura 1), pode-se observar que duas linhagens se destacaram em termos de produção e produtividade: a linhagem P40M2 $\left(294,33 \mathrm{Ug}^{-1}\right.$ após $24 \mathrm{~h}$ de cultivo) e a linhagem P27C3 (242,12 $\mathrm{Ug}^{-1}$ após $24 \mathrm{~h}$ de cultivo). Essas duas linhagens foram identificadas em um trabalho anterior (DELABONA et al., 2012), sendo a linhagem P40M2 pertencente à espécie Aspergillus fumigatus e a $\mathrm{P} 27 \mathrm{C} 3$ pertencente à espécie Aspergillus oryzae. A linhagem $\mathrm{P} 47 \mathrm{C} 3$, identificada como Aspergillus niger, também se destacou em termos da produção de endoglucanase $\left(351,79 \mathrm{Ug}^{-1}\right)$. No entanto, esse valor foi obtido somente após $120 \mathrm{~h}$ de cultivo, comprometendo a eficiência em termos do parâmetro produtividade. SONI et al.(2010) obtiveram uma produção máxima de endoglucanase pelo fungo $\boldsymbol{A}$. fumigatus de $98,5 \mathrm{Ug}^{-1} \mathrm{em}$ um estudo de seleção de substratos. Após a otimização das condições de cultivo, a atividade de endoglucanase aumentou para $240,2 \mathrm{Ug}^{-1}$ após 120 horas de cultivo. GRIGOREVSKI-LIMA et al. (2009) obtiveram atividade de endoglucanase pelo $A$. fumigatus de 21,06 $\mathrm{Ug}^{-1}$ após 96 horas de FES, utilizando uma combinação de bagaço de cana e água de maceração de milho como substrato. DHILLON et al.(2011) obtiveram uma atividade máxima de endoglucanase de 48,2 $\mathrm{Ug}^{-1}$ após 120 horas de FES em farelo de trigo, utilizando o fungo $\boldsymbol{A}$. niger. Como se pode observar, os valores reportados neste trabalho para as atividades de endoglucanase foram significativamente superiores aos relatados na literatura. Além disso, a maioria dos fungos avaliados apresentou atividades máximas de endoglucanase em períodos de cultivo entre 72 e120 horas, caracterizando uma vantagem em termos de aplicação destes fungos na produção dessas enzimas.

Em termos da atividade de $\beta$-glicosidase (Figura 2), a linhagem $\mathrm{P} 47 \mathrm{C} 3$ (A. niger) destacouse consideravelmente com relação tanto à produção quanto à produtividade, com valores de $\beta$-glicosidase de $62,31 \mathrm{Ug}^{-1}$ (após $72 \mathrm{~h}$ de cultivo) e $0,87 \mathrm{Ug}^{-1} \mathrm{~h}$, respectivamente. Todas as outras linhagens avaliadas apresentaram valores de produção inferiores a $40 \mathrm{Ug}^{-1}$. Da mesma forma que para a atividade de endoglucanase, os resultados obtidos para a atividade de $\beta$-glicosidase foram superiores ou da mesma ordem de grandeza aos relatados na literatura. GUPTE \& MADAMWAR(1997) avaliaram o cultivo isolado dos fungos $\boldsymbol{A}$. ellipticus e $\boldsymbol{A}$. fumigatus e obtiveram valores máximos de atividade de $\beta$-glicosidase de 11,75 e $7,65 \mathrm{Ug}^{-1}$, respectivamente, após 8 dias de cultivo em FES. DHILLON et al. (2011) obtiveram 
uma atividade máxima de $\beta$-glicosidase de $21,69 \mathrm{Ug}^{-1}$ após 96 horas de FES em farelo de trigo, utilizando o fungo $\boldsymbol{A}$. niger. GAO et al. (2008) reportaram valores de $\beta$-glicosidase de $128 \mathrm{Ug}^{-1}$ após 96 horas de cultivo do fungo A. terreus M11 em FES. Apesar de o fungo Trichoderma reesei ser um dos microrganismos mais estudados em relação à produção de celulases, uma vez que produz altas concentrações do complexo enzimático hidrolítico, a quantidade de $\beta$-glicosidase contida no complexo é relativamente baixa, acarretando uma desvantagem do ponto de vista do processo de sacarificação (KIM et al., 1997). Nesse sentido, a utilização do fungo Aspergillus niger tem sido apontada como alternativa para superar esta desvantagem, podendo ser avaliada em fermentações com culturas simples ou em co-culturas. Portanto, os resultados obtidos neste trabalho destacam a linhagem P47C3 (A. niger) como potencial para a produção de $\beta$-glicosidase, uma vez que este fungo apresentou um valor bastante interessante em termos de atividade em um tempo de cultivo de 72 horas.

Quanto à atividade de FPase (Figura 3), a linhagem $\mathrm{P} 75 \mathrm{P} 1$ se destacou em relação às demais linhagens em termos de produção $\left(2,25 \mathrm{Ug}^{-1}\right.$ após $120 \mathrm{~h}$ de cultivo) e produtividade $\left(0,058 \mathrm{Ug}^{-1} \mathrm{~h}\right)$. SONI et al.(2010) reportaram uma produção de FPase pelo $\boldsymbol{A}$. fumigatus de $3,37 \mathrm{Ug}^{-1}$ após 120 horas de cultivo em FES em um estudo de seleção de substratos. GUPTE \& MADAMWAR (1997) avaliaram o cultivo isolado dos fungos $\boldsymbol{A}$. ellipticus e $\boldsymbol{A}$. fumigatus e obtiveram valores máximos de atividade de FPase de 2,1 e $3,75 \mathrm{Ug}^{-1}$, respectivamente, após 8 dias de cultivo em FES. Os valores reportados no presente trabalho em termos de atividade de FPase são, portanto, da mesma ordem de grandeza ou superiores dos valores reportados na literatura, sendo que a maioria dos isolados avaliados apresentou atividades máximas para FPase em períodos de cultivo entre 24 e 72 horas.

$\mathrm{Na}$ figura 4, pode-se observar que, dos 40 isolados avaliados, o P6B2 (A. oryzae) foi o que apresentou a maior produção $\left(1076,94 \mathrm{Ug}^{-1}\right.$ após $72 \mathrm{~h}$ de cultivo) e produtividade $\left(34,85 \mathrm{Ug}^{-1} \mathrm{~h}\right)$ em termos da enzima xilanase. Muitas espécies de Aspergillus são reportadas na literatura como boas produtoras de xilanase. DHILLON et al. (2011) reportaram uma produção máxima de xilanase de $2604,06 \mathrm{Ug}^{-1}$ após 96 horas de cultivo do $\boldsymbol{A}$. niger em FES. COURI et al. (2000) obtiveram $76,55 \mathrm{Ug}^{-1}$ de xilanase após 42 horas de cultivo FES de uma linhagem mutante do fungo A. niger (3T5B8), utilizando farelo de trigo como substrato. MAMMA et al. (2008), utilizando

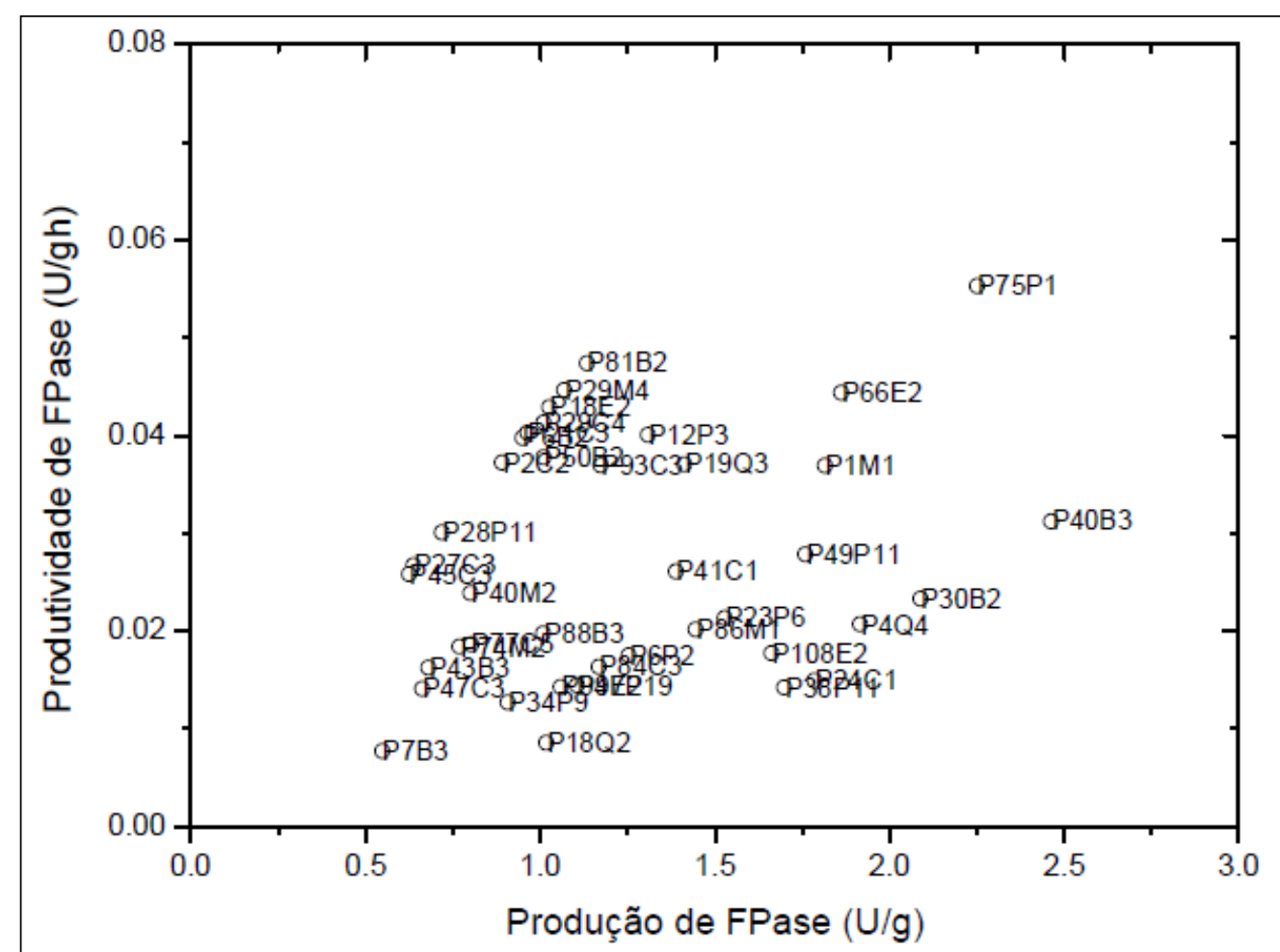

Figura 3 - Valores máximos de produtividade versus produção de FPase dos 40 fungos isolados da região Amazônica e cultivados em FES durante um total de 10 dias. 


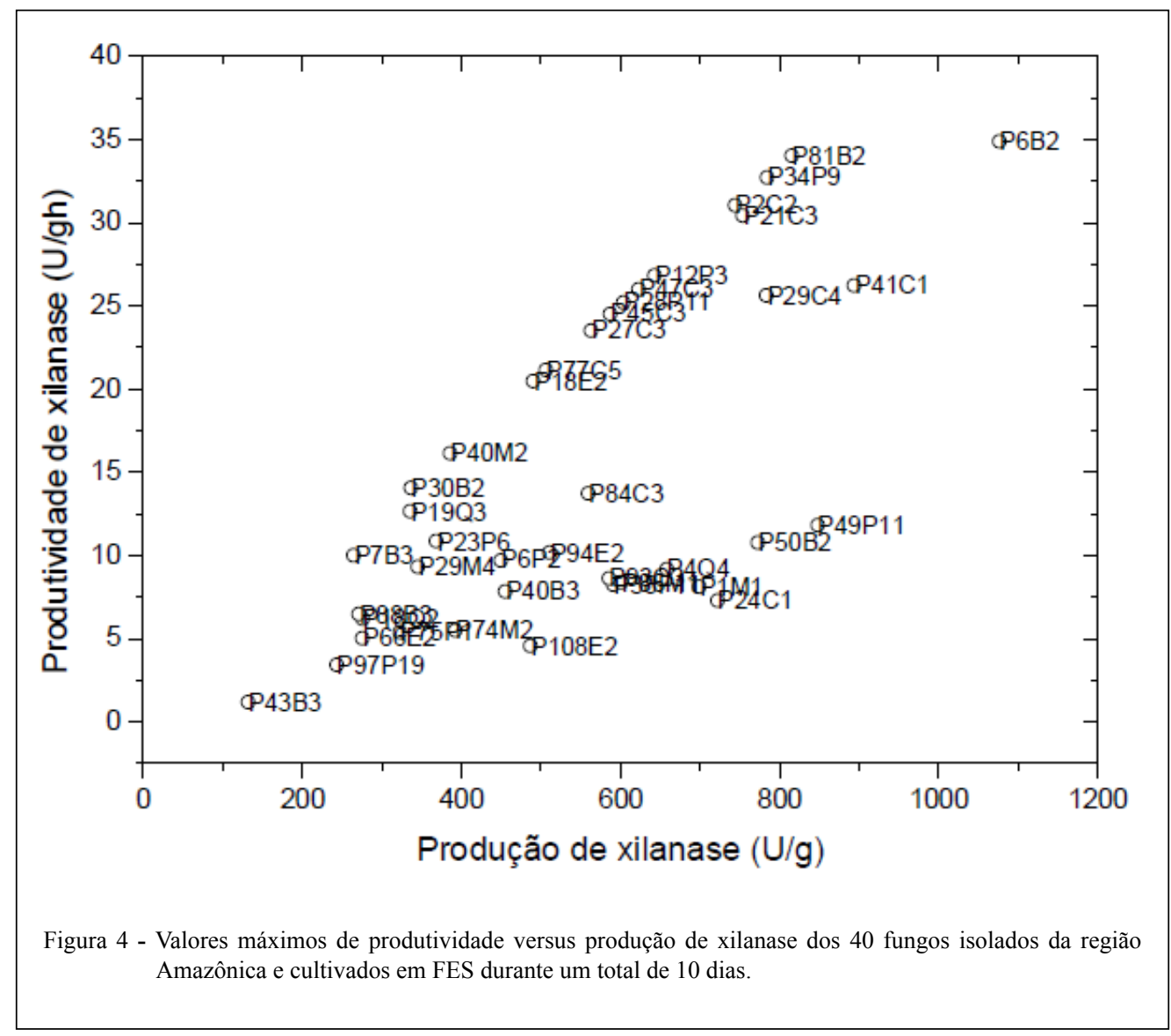

o fungo $\boldsymbol{A}$. niger em cultivo FES com casca de laranja como substrato, obtiveram uma atividade máxima de xilanase de $77 \mathrm{Ug}^{-1}$ durante 10 dias de cultivo. Os valores reportados neste trabalho em termos de atividade de xilanase são, na sua maioria, superiores aos valores reportados na literatura e apresentaram atividades máximas para xilanase em períodos de cultivo entre 24 e 72 horas.

Vale destacar que os fungos filamentosos são os microrganismos mais usados na produção de enzimas industriais e exibem características modelo para tal aplicação, tais comoa facilidade de cultivo e a produção de quantidades elevadas de enzimas extracelulares. Os fungos filamentosos, frequentemente usados na produção industrial das enzimas celulases e xilanases, são dos gêneros Trichoderma e Aspergillus (BHAT, 2000). Entre os fungos do gênero Aspergillus, o $A$. niger, juntamente com o $A$. oryzae são os dois fungos mais importantes a nível mundial para aplicações biotecnológicas (HU et al., 2011). No presente trabalho, um resultado bastante interessante observado foi que os fungos que mais se destacaram para a produção das enzimas celulases e xilanases, de uma forma geral, foram os isolados
P47C3 e P6B2, que pertencem às espécies de $\boldsymbol{A}$. niger e $A$. oryzae, respectivamente. Esses fungos filamentosos produziram uma quantidade expressiva das enzimas quantificadas em um intervalo de tempo relativamente curto (menor que 120 horas de cultivo), em comparação aos dados da literatura. Destaca-se que, em alguns desses trabalhos da literatura anteriormente citados, as condições de cultivo foram otimizadas, diferentemente deste trabalho, em que a caracterização da produção enzimática foi realizada em uma mesma condição de cultivo. Portanto, os isolados de fungos filamentosos selecionados aqui possuem um grande potencial para utilização em trabalhos futuros de otimização.

\section{CONCLUSÃO}

Os fungos isolados da região Amazônica que se destacaram quanto à produção e produtividade enzimática em termos de endoglucanase $\left(351,79 \mathrm{Ug}^{-1} \mathrm{em}\right.$ $120 \mathrm{~h})$ e $\beta$-glicosidase $\left(62,31 \mathrm{Ug}^{-1} \mathrm{em} 72 \mathrm{~h}\right)$ foram o $\mathrm{P} 47 \mathrm{C} 3$ (A. niger), enquanto que, para a xilanase $\left(1076,94 \mathrm{Ug}^{-1}\right.$ em $72 \mathrm{~h})$ e FPase $\left(2,46 \mathrm{Ug}^{-1}\right.$ em $\left.120 \mathrm{~h}\right)$, foram o P6B2 (A. oryzae) e o $\mathrm{P} 40 \mathrm{~B} 3$, respectivamente. Os resultados obtidos demonstram o enorme potencial de aplicação 
das enzimas produzidas pelos fungos isolados da região Amazônica, contribuindo, assim, para gerar os avanços tecnológicos necessários para o aumento da eficiência do uso da biomassa vegetal como fonte de energia renovável.

\section{AGRADECIMENTOS}

Os autores agradecem à Empresa Brasileira de Pesquisa Agropecuária (Embrapa) e à Coordenação de Aperfeiçoamento de Pessoal de Nível Superior (CAPES), pelo apoio financeiro, e ao pesquisador Dr. Paulino R. Villas Boas, pelo auxílio na análise dos dados e elaboração das figuras; ao prof. Dr. André Rodrigues, pelo auxílio na identificação dos isolados.

\section{REFERÊNCIAS}

BHAT, M.K. Cellulases and related enzymes in biotechnology. Biotechnology Advances, v.18, n.5, p.355-383, 2000. ISSN 0734 9750. Disponível em: <http://www.sciencedirect.com/science/ article/pii/S0734975000000410>. Acesso em: 25 fev. 2015.

COURI, S. et al. Hydrolytic enzyme production in solid-state fermentation by Aspergillus niger 3T5B8. Process Biochemistry, v.36, n.3, p.255-261, 2000. ISSN 1359-5113. Disponível em: <http:// www.sciencedirect.com/science/article/pii/S0032959200002090>. Acesso em: 25 fev. 2015.

DELABONA, P. et al. Using Amazon forest fungi and agricultural residues as a strategy to produce cellulolytic enzymes. Biomass \& Bioenergy, v.37, p.243-250, 2012. ISSN 0961-9534.

DHILLON, G.S. et al. Value-addition of agricultural wastes for augmented cellulase and xylanase production through solid-state tray fermentation employing mixed-culture of fungi. Industrial Crops and Products, v.34, n.1, p.1160-1167, 2011. ISSN 09266690. Disponível em: <http://www.sciencedirect.com/science/ article/pii/S0926669011001117>. Acesso em: 25 fev. 2015.

DODD, D.; CANN, I. Enzymatic deconstruction of xylan for biofuel production. Global Change Biology Bioenergy, v.1, n.1, p.2-17, 2009. ISSN 1757-1693.

DURAN, N. et al. Amazonian lignocellulosic materials-v screening of xylanolytic fungi. Applied Biochemistry and Biotechnology, v.53, n.2, p.155-162, 1995. ISSN 02732289. Disponível em: $<$ http://agris.fao.org/agris-search/ search.do?recordID=US9712586>. Acesso em: 25 fev. 2015.

GAO, J. et al. Production and characterization of cellulolytic enzymes from the thermoacidophilic fungal Aspergillus terreus M11 under solid-state cultivation of corn stover. Bioresource Technology, v.99, n.16, p.7623-7629, 2008. ISSN 0960-8524.

GHOSE, T. Measurement of cellulase activities. Pure and Applied Chemistry, v.59, n.2, p.257-268, 1987. ISSN 0033-4545.

GRIGOREVSKI-LIMA, A.L. et al. Aspergillus fumigatus thermophilic and acidophilic endoglucanases. Applied Biochemistry and Biotechnology, v.155, n.1-3, p.321-329, 2009. ISSN 0273-2289. Disponível em: <http://www.ncbi.nlm.nih.gov/ pubmed/19127443>. Acesso em: 25 fev. 2015.
GUPTE, A.; MADAMWAR, D. Solid state fermentation of lignocellulosic waste for cellulase and beta-glucosidase production by cocultivation of Aspergillus ellipticus and Aspergillus fumigatus. Biotechnology Progress, v.13, n.2, p.166-169, 1997. ISSN 87567938. Disponível em: <http://onlinelibrary.wiley.com/doi/10.1021/ bp970004g/abstract?systemMessage $=$ Wiley+Online+Library+will+ be+disrupted + on +21 st + March + from $+10 \% 3$ A $30+$ GMT $+\% 2806 \% 3$ A30+EDT $\% 29+$ for+up+to+six+hours+for+essential+maintenance .++Apologies+for+the+inconvenience. $>$. Acesso em: 25 fev. 2015.

HOLKER, U. et al. Biotechnological advantages of laboratoryscale solid-state fermentation with fungi. Applied Microbiology and Biotechnology, v.64, n.2, p.175-186, 2004. ISSN 0175-7598.

$\mathrm{HU}, \mathrm{H}$. et al. Improved enzyme production by co-cultivation of Aspergillus niger and Aspergillus oryzae and with other fungi. International Biodeterioration \& Biodegradation, v.65, p.248252, 2011.

KAMM, B.; KAMM, M. Principles of biorefineries. Applied Microbiology and Biotechnology, v.64, n.2, p.137-145, 2004. ISSN 0175-7598.

KIM, S.W. et al. Cellulase and xylanase production by Aspergillus niger KKS in various bioreactors. Bioresource Technology, v.59, n.1, p.63-67, 1997. ISSN 0960-8524. Disponível em: <http:// www.sciencedirect.com/science/article/pii/S0960852496001277>. Acesso em: 25 fev. 2015.

LYND, L. et al. Microbial cellulose utilization: Fundamentals and biotechnology. Microbiology and Molecular Biology Reviews, v.66, n.3, p.506, 2002. ISSN 1092-2172.

MAMMA, D. et al. Fungal multienzyme production on industrial by-products of the citrus-processing industry. Bioresource Technology, v.99, n.7, p.2373-2383, 2008. ISSN 0960-8524.

MANDELS, M.; STERNBERG, D. Recent advances in cellulase technology. Journal of Fermentation Technology, v.54, n.4, p.267-286, 1976. ISSN 0385-6380.

MEDEIROS, R.G. et al. Production of xylan-degrading enzymes from Amazon forest fungal species. International Biodeterioration \& Biodegradation, v.52, n.2, p.97-100, 2003. ISSN 0964-8305. Disponível em: <http://www.sciencedirect. com/science/article/pii/S0964830502001798>. Acesso em: 25 fev. 2015 .

MILLER, G. Use of dinitrosalicylic acid reagent for determination of reducing sugar. Analytical Chemistry, v.31, n.3, p.426-428, 1959. ISSN 0003-2700.

SONI, R. et al. Optimization of cellulase production by a versatile Aspergillus fumigatus fresenius strain (AMA) capable of efficient deinking and enzymatic hydrolysis of Solka floc and bagasse. Industrial Crops and Products, v.31, n.2, p.277283, 2010. ISSN 0926-6690. Disponível em: <http://www. sciencedirect.com/science/article/pii/S0926669009002283>. Acesso em: 25 fev. 2015.

ZHANG, Y.; LYND, L. Toward an aggregated understanding of enzymatic hydrolysis of cellulose: Noncomplexed cellulase systems. Biotechnology and Bioengineering, v.88, n.7, p.797824, 2004. ISSN 0006-3592. 